\title{
Strategi peningkatan kinerja Dinas Lingkungan Hidup dan Kehutanan dalam pencegahan kerusakan lingkungan hidup di Kabupaten Padang Lawas
}

\author{
Muhammad Saroha Lubis ${ }^{1}$, Sofyan Husein Siregar ${ }^{2}$, Samsir ${ }^{3}$ \\ ${ }_{1,2}^{1}$ Program Studi Magister Ilmu Lingkungan Pascasarjana Universitas Riau \\ ${ }^{3}$ Fakultas Ekonomi dan Bisnis Universitas Riau
}

\begin{abstract}
A performance enhancement strategy is a way that is done to better provide the potential in itself to achieve a goal. A performance enhancement strategy is an important thing to do as it can improve morals, loyalty, responsibility, discipline and, creativity and, well-being. The purpose of the author is to find out the perception of environment and forestry officers (DLHK) in the prevention of environmental damage and, to know DLHK's performance improvement strategy in the prevention of environmental damage in Padang Lawas district. Data used in this research is primary and secondary data, obtained through the data collection techniques triangulation are: observationand, interviewand questionnaire/poll. The Data obtained is analyzed using two analytical techniques namely qualitative descriptive analysis and SWOT analysis. After the analyst, it can be concluded that the perception of staff of Padang Lawas District in the prevention of environmental damage is carried out quite well. While the performance improvement strategies need to improve work and authority, improve the monitoring aspect, optimize budgets, make sanctions on employees who are less disciplined and, overcome cultural participation that is lacking in support and, promote a culture of caring environment to the entrepreneurs and society.
\end{abstract}

Keywords: Strategy; Performance Enhancemen; environmental

Lingkungan hidup Indonesia adalah karunia Tuhan Yang Maha Esa, setiap orang berhak hidup sejahtera lahir dan batin serta bertempat tinggal dan memperoleh pelayanan kesehatan yang baik. Pernyataan tersebut tertuang dalam Pasal 28 H Ayat (1) Undang-undang Dasar Negara Republik Indonesia Tahun 1945.

Perhatian pemerintah terhadap keberadaan perusahaan-perusahaan yang berorientasi pada aspek lingkungan diberikan melalui serangkaian kebijakan dan regulasi tentang lingkungan hidup. Diantaranya adalah dengan Undang-Undang Nomor 32 Tahun 2009 tentang Perlindungan dan Pengelolaan Lingkungan Hidup yang di dalamnya membahas tentang Analisis Mengenai Dampak Lingkungan (AMDAL) yang wajib dimiliki oleh perusahaan sebagai wujud tanggung jawab sosialnya. Undang-Undang Nomor 5 Tahun 2014 tentang Aparatur Sipil Negara bertujuan untuk meningkatkan independensi, netralitas, kompetensi, kinerja/produktivitas kerja, integritas, dan akuntabilitas.

Kabupaten Padang Lawas merupakan salahsatu Kabupaten yang berada di Provinsi Sumatera Utara dan berbatasan langsung dengan Bukit Barisan. Karenanya keberadaan dan peran DLHK di kabupaten ini sangat penting dalam pembangunan daerah pada masa depan khususnya terkait dengan perlindungan dan pengelolaan lingkungan hidup. Untuk mendapatkan suatu hasil yang berkualitas sangat ditentukan oleh Sumber Daya Manusia (SDM) yang ada di Dinas Lingkungan Hidup dan Kehutanan (DLHK) Kabupaten Padang Lawas. Dalam kinerja DLHK Kabupaten Padang Lawas belum optimal, sehingga banyak menghadapi kendala.

Penyelenggaraan rencana strategi Dinas Lingkungan Hidup dan Kehutanan Kabupaten Padang Lawas dalam perancanaan strateginya telah menetapkan visi, misi, tujuan dan sasaran, maka visi Dinas Lingkungan Hidup dan Kehutanan Kabupaten Padang Lawas Tahun 2014-2019 adalah "Mewujudkan Dinas Lingkungan Hidup dan Kehutanan Kabupaten Padang Lawas yang proaktif dan berperan dalam pengelolaan lingkungan".

Rencana Strategis (RENSTRA) Dinas Lingkungan Hidup dan Kehutanan Kabupaten Padang Lawas Tahun 2014-2019 ternyata belum optimal. Upaya pencegahan harus dumulai dari perencanaan hingga evaluasi, agar prinsip pembangunan berkelanjutan dapat diterapkan dalam mencegah dan mengendalikan keruskan lingkungan. Strategi peningkatan kinerja DLHK Kabupaten Padang Lawas Provinsi Sumatera Utara sangat berpengaruh terhadap lingkungan hidup sehingga agar tidak menimbulkan dampak negatif seperti banjir, asap, sampah dan rendahnya kesadaran masyarakat. 
Kendala atau kelemahan tersebut apabila tidak dapat diatasi secara efektif tentu akan berdampak pada tidak terwujudnya kinerja maksimal sebagaimana yang direncanakan. Pentingnya suatu kinerja yang berorentasi pembangunan di bidang lingkungan hidup, maka kajian berkenaan dengan Strategi Peningkatan Kinerja Dinas Lingkungan Hidup dan Kehutanan dalam Pencegahan Kerusakan Lingkungan Hidup di Kabupaten Padang Lawas Provinsi Sumatera Utara merupakan salah satu upaya untuk mewujudkan fungsi DLHK menjadi optimal.

Penelitian ini bertujuan untuk mengetahui persepsi pegawai DLHK Kabupaten Padang Lawas dalam pencegahan kerusakan lingkungan hidup dan, mengetahui strategi peningkatan kinerja DLHK dalam pencegahan kerusakan lingkungan hidup di Kabupaten Padang Lawas. Penelitian ini diharapkan dapat memberikan informasi terkait strategi yang perlu dilakukan oleh DLHK Kabupaten Padang Lawas dalam pencegahan kerusakan lingkungan hidup (Asfek Praktis) dan, menjadi bahan referensi pihak akademis dan dapat menambah ilmu pengetahuan dalam kehidupan manusia terkait Strategi Peningkatan Kinerja DLHK dalam Pencegahan Kerusakan Lingkungan Hidup (Aspek Teoritis).

\section{METODA PENELITIAN}

Penelitian dilakukan di Dinas Lingkungan Hidup dan Kehutanan (DLHK) Kabupaten Padang Lawas Provinsi Sumatera Utara pada bulan November 2018 sampai dengan Bulan Desember 2018. Instrumen penulis untuk dijawab oleh responden dalam bentuk angket/kuesioner, alat tulis, kamera, komputer, recorder untuk dokumentasi selama peroses kegiatan penelitian. Untuk memperoleh data primer wawancara terhadap responden dan data sekunder berupa dokumen dan literatur terkait penelitian.

Pendekatan penulisan dimulai pengumpulan data dari observasi, wawancara, pengisian kuesioner, analisis data dan penulisan. Pengumpulan data dengan mengajukan daftar pertanyaan secara sistematis yang berkaitan dengan keperluan penulis dengan aspek yang terkait kepada responden. Untuk mempermudah analisis dalam penelitian ini menggunakan skala likert seperti Tabel 1.

Tabel 1. Skala Likert

\begin{tabular}{lclcc}
\hline Tabel & Simbol & \multicolumn{1}{c}{ Keterangan } & $\begin{array}{c}\text { Skor } \\
\text { Nilai }\end{array}$ & $\begin{array}{c}\text { Persentase } \\
\text { Jawaban }\end{array}$ \\
\hline A & SS & $\begin{array}{l}\text { Sangat (setuju, baik, } \\
\text { suka,selalu) }\end{array}$ & 5 & $80-100$ \\
B & S & $\begin{array}{l}\text { Setuju (baik, suka, sering) } \\
\text { Cukup atau Netral }\end{array}$ & 4 & $60-79.99$ \\
C & N & $\begin{array}{l}\text { Tidak setuju (kurang baik atau } \\
\text { hampir tidak pernah) }\end{array}$ & 2 & $40-59.99$ \\
E & TS & Sangat (tidak setuju, buruk, tidak & $20-39.99$ \\
pernah atau kurang sekali) & 1 & $0-19.99$ \\
\hline
\end{tabular}

Sumber : Sugiono (2017)

Jenis data yang digunakan dalam penelitian ini berupa data kualitatif. Pengambilan sampel dilakukan secara random sampling. Kuesioner terdiri dari beberapa pernyataan persepsi pegawai dan, strategi peningkatan kinerja DLHK dalam pencegahan kerusakan lingkungan hidup di Kabupaen Padang Lawas. Teknik pengumpulan data dalam penelitian ini adalah teknik pengumpulan data dengan triangulasi (gabungan) yaitu: Observasi /pengamatan dan, Wawancara/interview serta Kuesioner/angket.

Subyek penelitian ini pegawai Dinas Lingkungan Hidup dan Kehutanan (DLHK) Kabupaten Padang Lawas Propinsi Sumatera Utara. Pegawai sebanyak 45 orang Kontrak dan 17 orang PNS (Renstra DLHK Kabupaten Padang Lawas 2014-2019). Dari jumlah pegawai tersebut diambil beberapa orang sebagai informan, pihak informan yang diwawancarai dapat dilihat pada Tabel 2. 
Tabel 2. Pihak Informan

\begin{tabular}{ll}
\hline Jabatan & Jumlah (Orang) \\
\hline Kepala DLHK Kabupaten Padang Lawas & 1 \\
Sekretaris & 1 \\
Kabid. Pengelolaan Sampah dan Limbah B3 dan & \\
Pengendalian & 1 \\
Kasi. Pencemaran dan Kerusakan Lingkungan & 1 \\
Kasi. Pemeliharaan Lingkungan Hidup & 1 \\
\hline Total & 5 \\
\hline
\end{tabular}

Langkah peneliti untuk memperoleh kredibilitas dan transferabilitas data adalah menggunakan tringulasi, yaitu data yang sudah diperoleh dari hasil wawancara, lalu dicek kembali dengan observasi, dokumentasi dan, dari hasil jawaban kuisioner serta dari literatur ilmiah lain.

Dalam penelitian ini variabelnya adalah strategi peningkatan kinerja Dinas Lungkungan Hidup dan Kehutanan (DLHK) dalam pencegahan kerusakan lingkungan hidup di Kabupaten Padang Lawas, secara konseptual pendapat Tengku (2005) dapat dilihat dari aspek organisasi, sumber daya manusia, pemerataan pembagian kerja, anggaran, sarana prasarana/ fasilitas, pelaksanaan monitoring, dampak sosial, dampak ekonomi, dampak Lingkungan dan Dukungan dari para stakeholder.

\section{Penyajian Dan Interpretasi Data}

Penyajian data dalam penelitian ini menggunakan dua teknik analisis yaitu analisis deskriptif kualitatif dan analisis SWOT yaitu:

Mengetahui Persepsi Pegawai DLHK Kabupaten Padang Lawas dalam Pencegahan Kerusakan Lingkungan Hidup. Untuk menghitung hasil jawaban kuisioner, maka digunakan rumus berikut (Sugiono, 2017):

$P=\frac{f}{n}: 100 \%$

Keterangan: $\quad \mathrm{P}=$ Persentase $(\%)$ yang dicari

$\mathrm{f}=$ Jumlah Reponden (orang) yang memilih alternatif jawaban

$\mathrm{n}=$ Jumlah keseluruhan Responden (orang)

Kriteria penilaian persentase persepsi pegawai DLHK ada pada Tabel 3.

Tabel 3. Kriteria Penilaian Persentase Persepsi.

\begin{tabular}{ll}
\hline Persentase (\%) & Kategori \\
\hline $80-100$ & Sangat Baik \\
$60-79.99$ & Baik \\
$40-59.99$ & Cukup \\
$20-39.99$ & Kurang \\
$0-19.99$ & Sangat Kurang \\
\hline
\end{tabular}

Sumber: Sugiono (2017) 
Langkah yang ditempuh, data yang bersumber dari hasil isian kuisioner diolah dengan cara mengalikan setiap poin jawaban dengan bobot yang sudah ditentukan dengan tabel bobot nilai. Berikut contoh sebagai gambaran, jika sebuah pertanyaan/pernyataan dengan ilustrasi 36 responden (orang)

1) Jawaban $\mathrm{SB}=4 \quad$ Responden $x 5=20$

2) Jawaban $B=7 \quad$ Responden $x 4=28$

3) Jawaban $\mathrm{C}=17 \quad$ Responden $\mathrm{x} 3=51$

4) Jawaban $\mathrm{K}=8 \quad$ Responden $\mathrm{x} 2=16$

5) Jawaban SK $=0 \quad$ Responden $x 1=0$

Akumulasi total skor adalah $20+28+51+16+0=115$

Untuk mengetahui hasil interpretasi, harus diketahui skor tertinggi (X) dan angka terendah (Y).

$\mathrm{X}=$ Skor tertinggi likert dikalikan jumlah responden (bobot nilai 5)

$\mathrm{Y}=$ Skor terendah likert dikalikan jumlah responden (bobot nilai 1)

Jumlah skor tertinggi untuk item SB ialah 5 × $36=180$, sedangkan item SK ialah 1 × $36=36$. Jadi, jika total skor responden diperoleh angka 115, maka penilaian interpretasi responden adalah hasil yang didapatkan dengan rumus indeks persentase $(\%)=\underline{\text { Total Skor }} \times 100$

$$
\begin{gathered}
\mathrm{Y} \\
=\underline{115} \times 100=63.8 \% \text { pembulatan angka } 64 \%
\end{gathered}
$$

Berdasarkan penilaian tersebut, akan dapat diketahui bagaimana Persepsi Pegawai DLHK Dalam Pencegahan Kerusakan Lingkungan Hidup di Kabupaten Padang Lawas.

\section{Mengetahui Strategi Peningkatan Kinerja Dinas Lingkungan Hidup dan Kehutanan dalam Pencegahan Kerusakan Lingkungan Hidup di Kabupaten Padang Lawas.}

Setelah pengisian kuesioner maka akan didapatkan penilaian terhadap tabel indikator faktor internal dan eksternal. Selanjutnya melakukan identifikasi unsur-unsur yang dikategorikan sebagai kekuatan (strength), kelemahan (weakness), Peluang (opportunity) dan ancaman (threat) yang dimiliki untuk strategi peningkatan kinerja DLHK dalam pencegahan kerusakan lingkungan hidup di Kabupaten Padang Lawas .

Untuk mendapatkan prioritas dan keterkaitan antara strategi, maka dari masing-masing indikator tersebut, dilakukan interaksi kombinasi dari strategi yang meliputi kombinasi internal-eksternal, yang terdiri dari:

1. Strategi strength - opportunity (SO); interaksi kombinasi strategi SO, yaitu suatu strategi yang menggunakan kekuatan untuk memanfaatkan peluang

2. Strategi strength - threat (ST) ; interaksi kombinasi strategi ST, yaitu suatu strategi yang menggunakan kekuatan untuk mengatasi ancaman

3. Strategi weakness- opportunity (WO) ; interaksi kombinasi strategi WO, yaitu suatu strategi yang meminimalkan kelemahan untuk memanfaatkan peluang

4. Strategi weakness- threat (WT) ; interaksi kombinasi strategi WT, yaitu suatu strategi yang meminimalkan kelemahan untuk mengatasi ancaman. 
Berikut adalah matriks SWOT untuk memperoleh prioritas dan keterkaitan antara strategi (Tabel 4).

Tabel 4. Matriks SWOT

\begin{tabular}{|c|l|l|}
\hline Internal & \multicolumn{1}{|c|}{ Strength } & \multicolumn{1}{|c|}{ Weakness } \\
\hline Opsternal & $\begin{array}{l}\text { Strategi SO, ialah suatu } \\
\text { strategi yang menggunakan } \\
\text { kekuatan untuk } \\
\text { memanfaatkan peluang }\end{array}$ & $\begin{array}{l}\text { Strategi WO, yaitu suatu } \\
\text { strategi yang meminimalkan } \\
\text { kelemahan untuk } \\
\text { memanfaatkan peluang }\end{array}$ \\
\hline Threat & $\begin{array}{l}\text { Strategi ST, yaitu suatu } \\
\text { strategi yang menggunakan } \\
\text { kekuatan untuk mengatasi } \\
\text { ancaman }\end{array}$ & $\begin{array}{l}\text { Strategi WT, yaitu suatu } \\
\text { strategi yang meminimalkan } \\
\text { kelemahan untuk mengatasi } \\
\text { ancaman. }\end{array}$ \\
\hline
\end{tabular}

\section{HASIL DAN PEMBAHASAN}

Sosok aparatur Dinas Lingkungan Hidup menurut Ghina dan Irwansyah (2017), hendaknya memiliki pengetahuan di berbagai permasalahan lingkungan dan kemampuan koordinasi serta kerjasama dengan berbagai pihak, seperti pengetahuan tentang sistem fisika, kimia, dan biologi serta memahami peroses-peroses industri dan teknologi produksi bersih.

Untuk mengetahui persepsi pegawai DLHK dalam pencegahan kerusakan lingkungan hidup di Kabupaten Padang Lawas, telah dilakukan pengisian kuesioner oleh 31 orang pegawai DLHK Kabupaten Padang Lawas sebagai responden internal dan 16 Dinas atau Instansi terkait (Stakeholder) sebagai responden eksternal. Persepsi pegawai DLHK Kabupaten Padang Lawas telah dapat dinilai hasilnya.

Secara umum persepsi pegawai DLHK Kabupaten Padang Lawas dalam pencegahan kerusakan lingkungan hidup yang dilihat dari aspek organsasi, SDM, pembagian kerja, anggaran dan saranaprasarana serta monitoring terlaksana dengan baik dengan tingkat penerapan mencapai angka total persentase 44,76\%, atau berdasarkan hasil internal cukup baik, dapat dilihat pada Tabel 5 .

Tabel 5. Total Persentase Tanggapan Responden Terhadap Faktor Internal

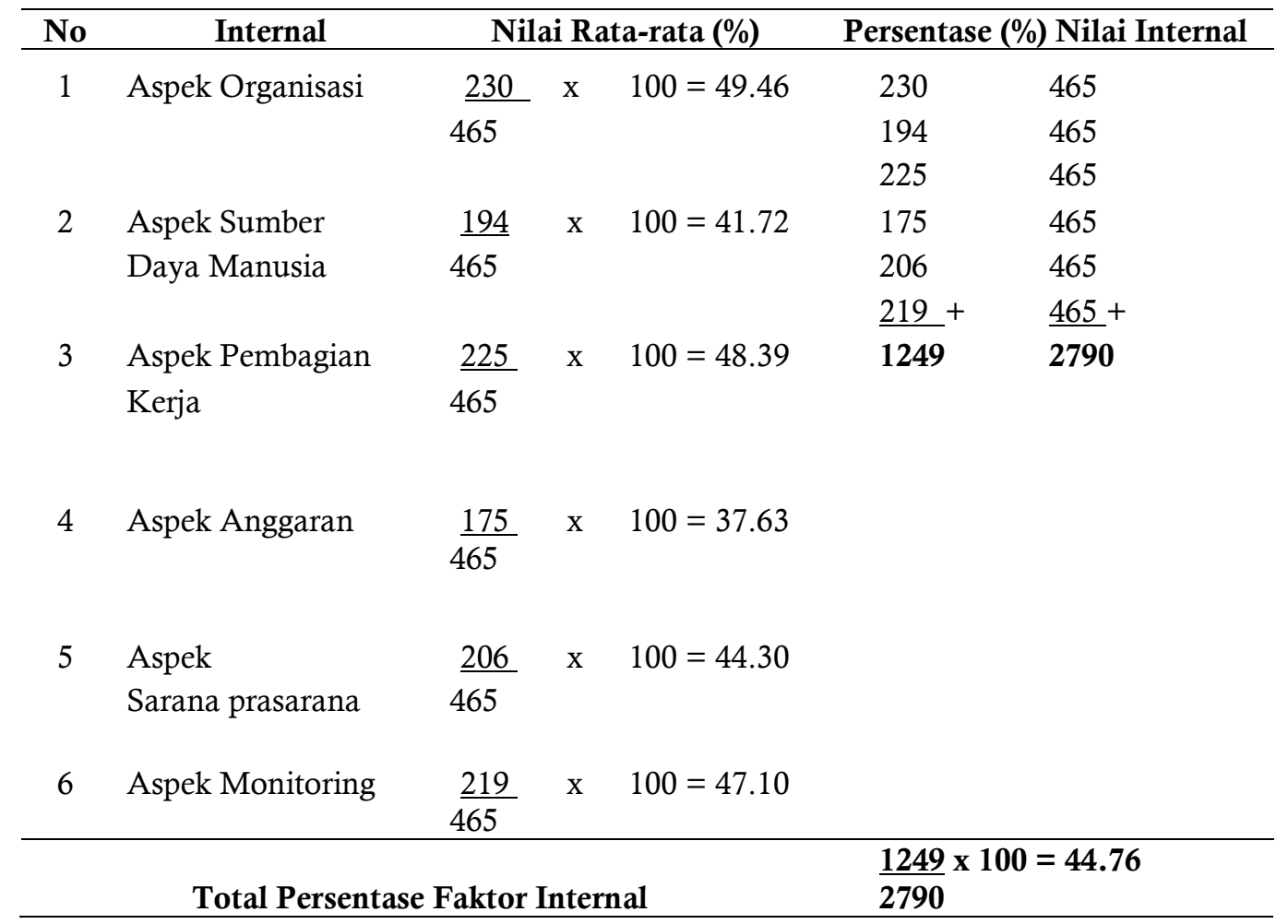




\section{Data olahan Kuesioner Internal}

Fakta pendukung dari hasil responden eksternal berkontribusi penilaian total persentase $52,68 \%$ atau kategori cukup baik, dapat dilihat pada Tabel 6 . Secara khusus pengadministrasian dan dokumentasi kinerja masih dalam pengawasan sebagai upaya perbaikan.

Tabel 6. Total Persentase Tanggapan Responden Tehadap Faktor Eksternal

\begin{tabular}{|c|c|c|c|c|c|c|}
\hline \multirow{2}{*}{$\begin{array}{l}\text { No } \\
1\end{array}$} & \multirow{2}{*}{$\begin{array}{l}\text { Eksternal } \\
\text { Dampak }\end{array}$} & \multicolumn{3}{|c|}{ Nilai Rata-rata (\%) } & \multicolumn{2}{|c|}{ Persentase (\%) Nilai Ekternal } \\
\hline & & $\underline{132}$ & $\mathrm{x}$ & $100=55$ & 132 & 240 \\
\hline & Ekonomi & $\overline{240}$ & & & 125 & 240 \\
\hline & & & & & 115 & 240 \\
\hline \multirow[t]{2}{*}{2} & Dampak & $\underline{125}$ & $\mathrm{x}$ & $100=52.08$ & $\underline{218}+$ & $400+$ \\
\hline & Sosial & $\overline{240}$ & & & $\overline{590}$ & $\overline{1120}$ \\
\hline \multirow[t]{2}{*}{3} & Dampak & $\underline{115}$ & $\mathrm{x}$ & $100=47.91$ & & \\
\hline & Lingkungan & 240 & & & & \\
\hline 4 & Stakeholder & $\frac{218}{400}$ & $\mathrm{x}$ & $100=54.5$ & & \\
\hline Tot: & Persentase Eksternal & & & & \multicolumn{2}{|c|}{$\frac{590}{1120} \times 100=52.68$} \\
\hline
\end{tabular}

Hasil identifikasi melalui pengisian kuesioner terhadap kinerja pegawai DLHK Kabupaten Padang Lawas dalam pencegahan kerusakan lingkungan hidup pada Tabel 5 dan 6 mencapai kategori "cukup". Lebih jauh dalam pelaksanaan Peraturan Pemerintah Nomor 27 Tahun 1999 tentang Analisis Mengenai Dampak Lingkungan, diterangkan: Dalam rangka melaksanakan pembangunan berwawasan lingkungan hidup sebagai upaya sadar dan berencana mengelola semberdaya secara bijaksana dalam pembangunan yang berkelanjutan untuk meningkatkan kesejahteraan dan mutu hidup, perlu dijaga keserasian antar berbagai usaha dan atau kegiatan.Kaitan Peraturan Pemerintah Nomor 27 Tahun 1999 masih jauh dari yang dicita-citakan. Fakta pendukung adalah mencapai angka persentase $44,76 \%$, (Internal) dan 52,68\% (Eksternal).

Rangkuti (2004) mengemukakan, berdasarkan hasil identifikasi terhadap suatu organisasi, perlu ada institusi yang berwenang untuk memberikan keputusan, dan menentukan tingkat kelayakan perlu analisis yang mendalam berdasarkan penelitian kajian ilmiah, baik terhadap analisis lingkungan internal maupun analisi eksternal organisasi. Setelah diidentifikasi strategi penigkatan kinerja DLHK dalam pencegahan kerusakan lingkungan hidup di Kabupaten Padang Lawas melalui kuesioner dan melakukan wawancara dengan beberapa responden, maka dapat dilakukan melalui analisis SWOT, bertujuan untuk mempertegas aspek-aspek mana yang merupakan kekuatan dan kelemahan, aspek mana pula yang menjadi peluang dan ancaman.

Nawawi (2001) mengemukakan identifikasi isu strategis merupakan tahapan yang paling krusial dari proses penilaian kinerja. Isu strategis merupakan suatu kondisi yang membutuhkan tanggapan organisasi melalui penetapan suatu kebijakan yang mampu berkembang kearah yang lebih baik di masa depan. Hasil analisis terhadap lingkungan strategis yang telah dilakukan dari lingkungan internal akan tergambar aspek apa saja yang menjadi kekuatan (Strengths) dan kelemahan (Weaknesses). Sedangkan dari lingkup eksternal diperoleh gambaran mengenai peluang (Oppurtunities) dan ancaman (Threats) yang dihadapi DLHK saat ini.

\section{Kekuatan (Strengths)}

Kualitas sumberdaya aparatur DLHK Kabupaten Padang lawas bila di tinjau dari segi pendidikan formal secara global adalah $66.45 \%$, (berada pada kategori "baik") dan memiliki kewenangan dalam pengelolaan lingkungan hidup berdasarkan Peraturan Daerah Kabupaten Padang Lawas Nomor 05 Tahun 2016 tentang Pembentukan dan Susunan Perangkat Daerah Kabupaten Padang Lawas dan Peraturan Bupati Padang Lawas Nomor 32 Tahun 2016 tentang Susunan dan Organisasi Tata Kerja Perangkat Daerah Kabupaten Padang Lawas.

\section{Kelemahan (Weaknesses)}

Kemampuan pegawai bidang pencegahan kerusakan lingkungan hidup rendah, terbatasnya sarana dan prasarana untuk pelaksanaan tugas dengan baik dan, budaya kerja staft belum disiplin dan minim dengan kreativitas serta, koordinasi antar bidang dalam organisasi masih rendah. 


\section{Peluang (Oppurtunities)}

Adanya penerapan sanksi ekonomi terhadap unit/usaha yang melanggar peraturan lingkungan hidup dan, adanya partisipasi dari perusahaan terhadap masyarakat melalui bantuan CSR serta, adanya perbaikan kondisi dan kualitas lingkungan hidup serta mencegah proses degradasi lingkungan.

\section{Ancaman (Threats)}

Kurangnya koordinasi antara DLHK dengan beberapa dinas/stansi terkait dan para pengusaha serta Lembaga Suadaya Masarakat sekitar dan, kurangnya partisipasi dan kesadaran masyarakat tentang pentingnya mempertimbangkan aspek lingkungan serta, rendahnya kepatuhan para pengusaha terhadap baku mutu lingkungan. Setelah mengkombinasikan beberapa komponen SO (Strengths- Oppurtunities), WO (Weaknesses- Oppurtunities), ST (Strengths- Threats), WT (Weaknesses- Threats). Hasil kombinasi faktor internal dan eksternal dapat dijadikan sebagai strategi peningkatan kinerja Dinas Lingkungan Hidup dan Kehutanan dalam pencegahan kerusakan lingkungan hidup di Kabupaten Padang Lawas. Dapat dilihat pada Tabel 7.

Tabel 7. Hasil Identifikasi menggunakan Matriks SWOT

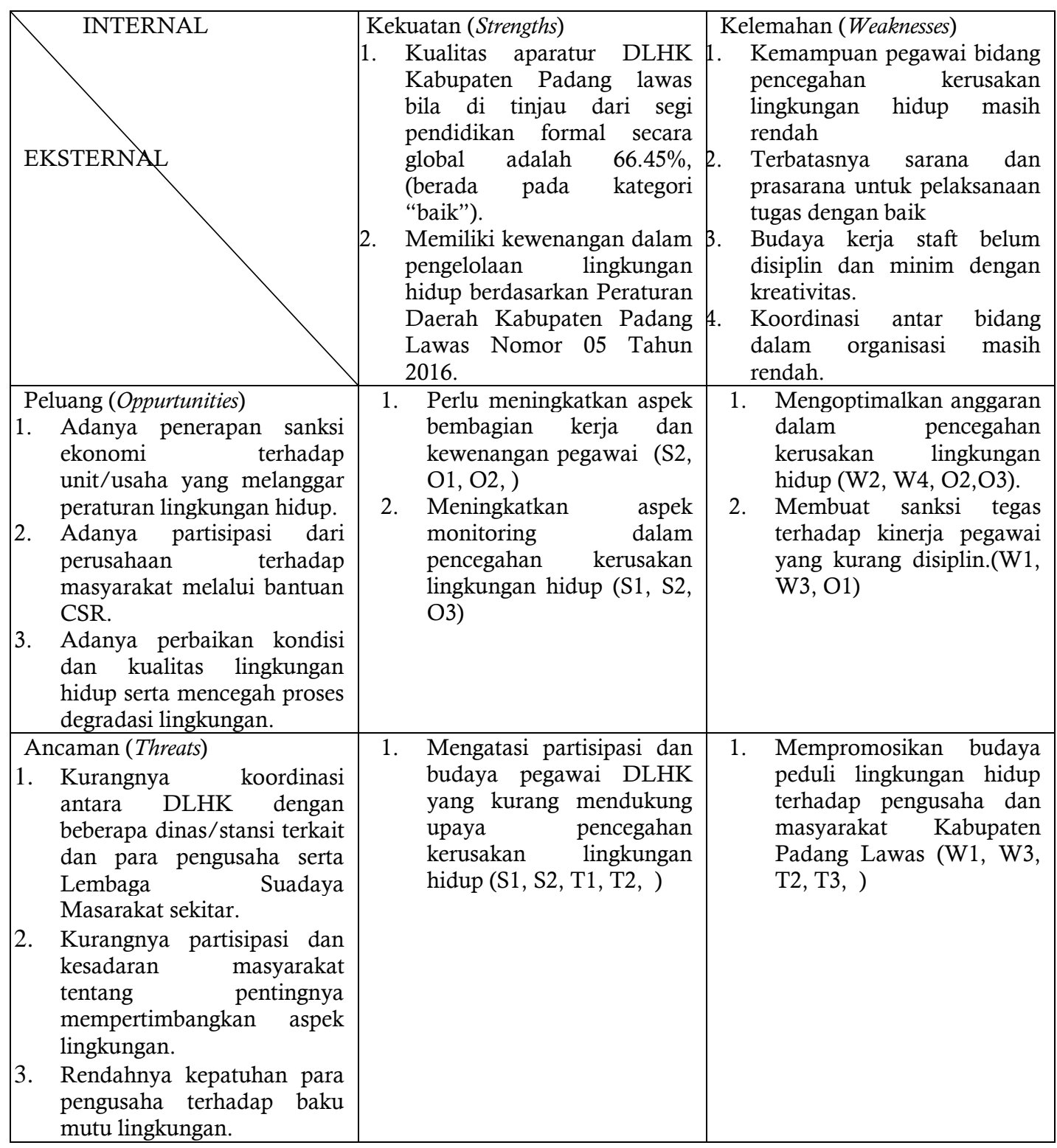


Dari Tabel 7 hasil identifikasi menunjukkan, strategi yang digunakan dalam menentukan Strategi Peningkatan Kinerja DLHK dalam Pencegahan Kerusakan Lingkungan Hidup yaitu:

1) Strategi SO (Strengths and Oppurtunities) strategi yang mengoptimalkan aspek kekuatan untuk memanfaatkan peluang yaitu. Meningkatkan aspek bembagian kerja dan kewenangan pegawai dan, meningkatkan aspek monitoring dalam pencegahan kerusakan lingkungan hidup.

2) Strategi WO (Weaknesses and Oppurtunities) strategi yang meminimalkan aspek kelemahan untuk memanfaatkan peluang yaitu. Mengoptimalkan anggaran dalam pencegahan kerusakan lingkungan hidup dan, membuat sanksi tegas terhadap kinerja pegawai yang kurang disiplin.

3. Strategi ST (Strengths and Threats) strategi yang menggunakan aspek kekuatan yang dimiliki untuk mengatasi ancaman yang dihadapi perlu mengatasi partisipasi dan budaya pegawai DLHK yang kurang mendukung upaya pencegahan kerusakan lingkungan hidup.

4. Strategi WT (Weaknesses and Threats) strategi yang meminimalkan aspek kelemahan dan menghindari ancaman dengan mempromosikan budaya peduli lingkungan hidup terhadap pengusaha dan masyarakat Kabupaten Padang Lawas.

\section{KESIMPULAN}

Persepsi Pegawai DLHK Kabupaten Padang Lawas dalam Pencegahan Kerusakan Lingkungan Hidup, secara umum terlaksana dengan cukup baik, dibuktikan dengan tingkat penerapan mencapai angka persentase $44,76 \%$, atau berdasarkan hasil penilaian responden internal kategori cukup baik. Fakta pendukung dari hasil responden eksternal memberikan penilaian di angka persentase 52,68\%, atau kategori cukup baik. Strategi Peningkatan Kinerja DLHK dalam Pencegahan Kerusakan Lingkungan Hidup di Kabupaten Padang Lawas ialah: Meningkatkan aspek bembagian kerja dan kewenangan pegawai, meningkatkan aspek monitoring dalam pencegahan kerusakan lingkungan hidup, mengoptimalkan anggaran dalam pencegahan kerusakan lingkungan hidup, membuat sanksi tegas terhadap kinerja pegawai yang kurang disiplin dan, mengatasi partisipasi dan budaya pegawai yang kurang mendukung upaya pencegahan kerusakan lingkungan hidup serta, mempromosikan budaya peduli lingkungan hidup terhadap pengusaha dan masyarakat Kabupaten Padang Lawas. Disampaikan saran, untuk meningkatkan kinerja. Setiap pegawai harus meningkatkan kompetensi individu, membangun komitmen kolektif dan menjadikannya sebagai paradigma untuk menumbuhkan kesadaran yang ikhlas, melakukan inventarisasi terhadap sumber pencemaran yang ada, mempriorotaskan kemampuan teknis aparatur, perlu ada jaminan bagi pegawai yang telah di didik secara teknis untuk tidak dimutasikan paling tidak dalam waktu lima tahun supaya memiliki kesempatan untuk mengembangkan pengetahuan yang di miliki kepada pegawai lain, serta harus trans paran.

\section{DAFTAR PUSTAKA}

Ghina, H.P.M. dan Irwansyah. 2017. Efektivitas Fungsi Badan Lingkungan Hidup Daerah terhadap Pemberian Proper di Bidang Pertambangan. Jurnal Pagaruyuang. 1 (1): 2580-4227.

Nawawi, H. 2001. Perencanaan SDM untuk Organisasi Profit yang Kompotitif. Gadjah Mada University Press. Yogyakarta.

Presiden Republik Indonesia. 2009. Undang-Undang No. 32 Tahun 2009 tentang Perlindungan dan Pengelolaan Lingkungan Hidup. Sekretariat Negara. Jakarta.

Presiden Republik Indonesia. 2014. Undang-Undang No. 5 Tahun 2014 tentang Aparatur Sipil Negara. Sekretariat Negara. Jakarta

Rangkuti, F. 2015. Teknik Pembedahan Kasus Bisnis Analisis SWOT. Gramedia Pustaka Utama. Jakarta.

Sugiono. 2017. Metode Penelitian Pendidikan. Alfabeta. Bandung.

Tengku, N. 2005. Efektivitas Kinerja Organisasi Badan Pengendalian Dampak Lingkungan Daerah Kabupaten Pelalawan dalam Pengelolaan Lingkungan Hidup. Tesis, Program Pascasarjana Universitas Riau, Pekanbaru (Tidak diterbitkan). 